\title{
Integrative Responses of Leaf-Cutting Ants to Temperature Rises
}

\section{Cleverson de Sousa Lima, André Frazão Helene, Agustín Camacho}

3 Department of Physiology, Institute of Biosciences, University of São Paulo. São Paulo, SP, Brazil.

4 * Correspondence:

$5 \quad$ agus.camacho@gmail.com

6 Keywords: critical thermal maximum, voluntary thermal maximum, Atta sexdens, body size, 7 dehydration, start temperature, heating rate, relative humidity.

\section{Summary Statement}

9 Here we show how internal (body size, hydration level) and external factors (heating rate, relative

10 humidity) affect leaf-cutting ants behavioral and physiological responses to temperature rises.

\section{Abstract}

12 Thermal variation has complex effects on organisms and they deal with it by combining behavioral

13 and physiological thermal tolerance. However, we still do not understand well how these two types 14 of traits relate to body condition (e.g. size, hydration) and environmental variables (e.g. relative 15 humidity), some of which are typical aspects of thermal tolerance experiments (warming rates, start 16 temperature). We explored these interactions using a set of experiments that sequentially measure 17 behavioral (Voluntary Thermal Maxima) and physiological thermal tolerance (Critical Thermal 18 Maxima) for individuals of Atta sexdens rubropilosa (Forel, 1908). We found non-linear effects of 19 body size on behavioral thermal tolerance and refuted the traditional hypothesis that body size 20 increases ant's physiological thermal tolerance. Hydration state and humidity had complex effects on 21 behavioral and physiological tolerance. However, both tolerance measures increased with heating 22 rates and start temperature. Our work helps understanding how an ectotherm integrates stimuli 23 affecting its thermal tolerance to decide which temperatures to avoid. We discuss implications for the 24 ecology of ants, their labor division, and for their susceptibility to climate warming and drought.

\section{Introduction}


The climate crisis (Pachauri et al., 2014) makes it necessary to understand how organisms will respond to thermal stress in different contexts. While many studies have regarded variation in different parameters of organisms' thermal tolerance (e.g. Angilletta et al., 2007; Cerdá et al., 2002; Christian \& Morton, 1992), a fundamental and less understood aspect of this problem concerns how organisms integrate behavioral and physiological thermal tolerance to cope with temperature rises at the microhabitat scale.

Rises in environmental temperature have non-linear effects on physiological functions of ectothermic organisms (Angilletta, 2009; Camacho et al., 2018; Huey and Stevenson, 1979), and neural changes precede heat coma and CTmax (Jørgensen et al., 2020). At tolerable thermal levels, different aspects of physiological performance can be optimized within specific intervals (stamina, sprint speed, Huey, 1984). Nonetheless, excessively high temperatures will block these physiological processes and can kill animals in a short time (Angilletta et al., 2007; Christian and Morton, 1992; Ribeiro et al., 2012), for example, when animals attain their Critical Thermal Maxima (CTmax, Cowles and Bogert, 1944). At temperatures close to such levels, animals often move away from heat sources, exhibiting a Voluntary Thermal Maximum (VTM, Cowles \& Bogert, 1944; Camacho et al., 2018) that can be conserved within species across their geography and history (Camacho \& Rusch 2017, Wiens et al 2019).

Assuming that the VTM is, as CTmax is, a physiological thermal tolerance related effect, it is reasonable to expect that internal and environmental conditions of an organism must define the behavioral thermal avoidance. For example, since thermal tolerance of ants (i.e. their CTmax) can be affected by several factors (e.g. Ribeiro et al 2012), it could be expected that behavioral thermal tolerance dynamically responds to them, assuming that behavior has been selected to maintain organisms within optimal, or even lower thermal levels (Huey \& Martin, 2009). Factors that may alter physiological thermal tolerance can be divided into traits of the organism and of the environment. For instance, body size is an overarching trait that affects many physiological (Jensen and Nielsen, 1975; Hurlbert et al., 2008) and ecological traits (Kaspari, 1993; Johnson, 2008; Baudier et al., 2015). This trait is known for raising the critical thermal limits of vertebrate and invertebrate ectothermic species (Angilletta et al., 2007; Christian and Morton, 1992, Ribeiro et al., 2012). Larger bodies have lower water loss rates, can store more water, and, in small arthropods' case (i.e. ants), may help separating the body from heated surfaces, if associated to longer limbs (Kaspari and Weiser, 2002). Nonetheless, few data exist regarding the relationship between CTmax and body size in insects (e.g. Ribeiro et al., 2012; Verble-Pearson et al., 2015). In Atta sexdens, body size present 
large differences among different casts, which execute different tasks within a colony (Hölldobler and Wilson, 1990). In this way, observing body size effects on thermoregulation and thermal tolerance might help to understand constrains on the engagement on different tasks.

The level of body hydration (HL) can be another organismal trait regulating thermal tolerance among ectothermic animals. Body water loss rates increase with rising body temperatures (Edney, 1977; Lighton and Bartholomew, 1988) and lower the CTmax and VTM of some ectotherms (e.g. Anurans, Anderson and Andrade, 2017). Small arthropods also react to water stress (Denlinger and Yocum, 1998), by foraging closer to their refuges (Lighton et al., 1994) or selecting resources with higher water content (Bowers and Porter, 1981), or recruiting individuals with specific smaller size to transport water to the anthill (Ribeiro and Navas, 2008). Knowing whether dehydrated individuals lower their VTMs to protect themselves from lower CTmax values should help us understand how dehydration may trigger thermally induced changes in microhabitat use and activity (Rozen $\square$ Rechels et al, 2019). Yet, to our knowledge, such effect of dehydration has not been detected for arthropods.

Apart from these traits, some environmental conditions may also increase the risks of overheating and dehydration, and, consequently, induce changes in either behavioral and physiological thermal tolerance. For example, higher heating rates could lead an organism (ex. an ant) to seek thermal refuge at lower temperatures, in anticipation of a higher risk of exceeding their CTmax. In turn, a slower heating rate, involving longer exposure to sublethal temperatures, might also induce greater physiological stress, especially if that happens within a more drying environment. If such conditions lower an organism's CTmax, is possible to expect a decrease in voluntary thermal maxima, under the above presented premise of selection on behavior. These conditions can be manipulated by controlling heating rates (HR) and start temperatures (ST), and the air relative humidity (RH), during thermal tolerance assays (Terblanche et al., 2007; Camacho et al., 2018). Thus, observing their effect on serial measures of the VTM and CTmax should help us better appreciate the integration of behavioral and physiological thermal tolerance, and how our experimental set ups influence such understanding.

The small size and big number of ants make them useful experimental models for thermal tolerance studies. Leaf-cutting ants Atta sexdens rubropilosa (Forel, 1908) also present the particularity that their casts differ in size and tasks. Thus, observing thermal tolerance changes with body size and environmental conditions, might shed light on their labor division. Herein, we tested if 
the start temperature and heating rate, and (3) a combination of body hydration level and air's relative

89 humidity.

\section{Materials and Methods}

90

91

92

93

\subsection{Study animals}

Ants were supplied by the Laboratório de Ciências da Cognição (Department of Physiology, Institute of Biosciences, University of São Paulo). Six adult colonies were used. Specifically, our ants come from six colonies, raised in the laboratory at $24{ }^{\circ} \mathrm{C}$ and $75 \% \sim 85 \%$ relative humidity, and fed every day with leaves of Acalypha spp.

\subsection{The Thermal Tolerance Meter}

We developed a device capable of sequentially measuring ants' VTM and CTmax in about 15 minutes (Fig. 1). In this device, four animals are simultaneously heated in individual identical chambers with a small thermal refuge, inserted within a thermal bath. Ants' body temperature is monitored by a T-type thermocouple (1 mm diameter, Omega (C), inserted in a freshly dead ant. That ant is always similarly sized to the ones being heated and its thermocouple is connected to a computer through a datalogger (Picolog® TC H8). After the onset of warming, each individual's VTM is registered as the body temperature measured when the ant enters and remain in the thermal refuge for at least 7 seconds. As temperature keeps raising within the thermal refuge, ants move back to the heating tube and enter thermal equilibria with the other ants and the model (see supplementary material file S1). Heating continues and then, CTmax is recorded as the body temperature at which each ant has its hind legs paralyzed, disorganizing its locomotion.

\subsection{Experiments}

\subsubsection{Effects of body size on VTM and CTmax}

We measured the VTM and CTmax of 49 individuals with varying sizes (1.5-4 $\mathrm{mm}$ of head width). Size was measured with an analogic caliper (accuracy: 0.001m.). For this set of measurements, we used $\mathrm{ST}=25^{\circ} \mathrm{C}$ and $\mathrm{HR} \sim 1^{\circ} \mathrm{C} / \mathrm{min}$. 
The VTM and CTmax of individuals with hydration ranging 100-75\% were tested at

115 environmental $\mathrm{RH}$ of $50 \%$ and $85 \%$, always using individuals of $2.3 \mathrm{~mm}$ in head width, ST $=25^{\circ} \mathrm{C}$

116 and $\mathrm{HR} \sim 1^{\circ} \mathrm{C} / \mathrm{min}$. The experiments were carried out in a controlled climatized room. The RH of the

117 air and inside thermal chambers was similar, as checked using a hygrometer (HT-600 Instrutherm).

118 Keeping probes measuring humidity within the thin thermal chambers was impossible, but even if

119 some unnoticed variation in RH might happen during heating, it can be safely assumed that tubes at

$12050 \%$ remained always much drier than the ones at $85 \%$.

\subsubsection{Combined effects of heating rate and start temperature on VTM and CTmax}

Within our heating chamber, we heated ants using rates between $0.5^{\circ} \mathrm{C} /$ minute and $3.5^{\circ} \mathrm{C} /$ minute. Along these tests, we also varied ST between $23^{\circ} \mathrm{C}$ and $33^{\circ} \mathrm{C}$. For this evaluation, we only used ants with $2.3 \mathrm{~mm}$ in head width, directly taken from the colonies.

\subsection{Data analyses}

We tested for all these effects, separately, fitting Linear Mixed Models (Bates et al., 2014) that related either the VTM or the CTmax with the described predictors. Thus, in each fitted model,

128 either the VTM or CTmax was the response variable, and the corresponding predictors entered as 129 fixed factors. The source colony for each ant entered as random factor to control for lack of 130 independence in traits among sister ants.

When testing the effects of BS on the VTM and CTmax, we observed that average workers 132 might present higher VTM than both, smaller and larger ones. Because of that, we obtained 133 additional measurements on these same conditions and compared the fit of non-linear and linear 134 relationships between ants' size and VTM. We used the Akaike Information Criterion (AIC, Akaike, 135 1974) to choose the model with lowest values among three models: A first order one, or straight line, 136 a second order one, describing a quadratic increase/decrease, and third order polynomial model, 137 describing a parabolic trajectory.

138 When testing for the influence of the relative importance between HL and RH on VTM and 139 CTmax, we used the Akaike's information criterion to select between three competing models: (1) no 140 effect, (2) interaction between HL and RH, (3) no interaction between them.

$141 \quad$ All analyses were performed in the R environment (R Development Core Team, 2018) using 142 the package nlme (Pinheiro et al., 2017). 


\section{Results}

143

\section{Discussion} 0.003 ) (Fig. 2C).

\section{Discussion}

\subsection{Body size effect on VTM and CTmax}

BS didn't show linear correlations with VTM $(\mathrm{N}=49$, B: 0.13014 , p: 0.6571$)$ or CTmax $(\mathrm{N}=$ 49, B: 0.18545, p: 0.6214). However, a polynomial relationship of third order explained better the variation in VTM than a straight line, as indicated by a difference larger than 20 Akaike units (1st degree $=226,168,2$ nd degree $=224,408$ and 3rd degree $=205,112$ ). That indicates that average-sized workers (with 2 2.6mm head width) consistently exhibited higher VTM, despite showing no differences in CTmax (Fig. 2A).

\subsection{Effects of Heating rate and start temperature on VTM and CTmax}

Raising the HR increased both, ants' VTM (N = 57; B: 1.18781, p: 0.0073) and CTmax (N = 57; B: 1.77384, p: 0.0001 ), making VTMs range from $30^{\circ} \mathrm{C}$ to $37.8^{\circ} \mathrm{C}$ and $\mathrm{CTmax}$ from $40.6^{\circ} \mathrm{C}$ to $48^{\circ} \mathrm{C}$ (Fig. 2B). On the contrary, ST had no visible effects on either ants' VTM (N = 45; B: 0.042469 p: 0.6653) or CTmax ( $=45$; B: 0.00335, p: 0.9445).

\subsection{Combined effects of hydration level and relative humidity on VTM and CTmax}

Regarding the VTM, the full model without the interaction rendered the lowest AIC (7 units below the second one). According to it, only HL affected ants VTM, positively $(\mathrm{N}=40$, Nests $=5$, $\mathrm{B}=0.1571, \mathrm{SD}=0.02, \mathrm{t}=5.6, \mathrm{p}: 0.000)$.

With respect to CTmax, the full model without interaction again rendered the lowest AIC (4 units below the second one). On this model, both hydration and RH had positive effects on CTmax, with relative umidity having stronger effects (Hydration: $\mathrm{N}=40$, Nests $=5, \mathrm{~B}=0.4129, \mathrm{SD}=0.0169$, $\mathrm{t}=2.4426$, p: 0.020; Humidity: $\mathrm{N}=40$, Nests=5, $\mathrm{B}=0.110853, \mathrm{SD}=0.0273145, \mathrm{t}=4.058415, \mathrm{p}$ :

Our most striking finding is that average-sized workers "dare" to get closer to their CTmax, compared to smaller or larger sister ants. Medium-sized individuals belong to a worker cast which spends more time outside the colony, foraging (Wilson, 1980). Thus, our results open the possibility that labor predisposition in ants, instead of being explained by body size alone (Wilson, 1980), might 
168

169

170

171

172

173

174

175

176

177

178

179

180

181

182

183

184

185

186

187

188

189

190

191

192

193

194

195

196

197

198

correspond with the development of specific tolerance thresholds (e.g. the VTM) that manage the probability of engaging in different tasks. Considering that neural dysfunctions precede physiological changes (Jørgensen et al., 2020), it is possible to speculate that behavioral and/or physiological aspects can be differentiated for small and large sister ants, along their ontogeny. Among hymenopterans, it is common that the separation of reproductive and working casts is supported by feeding with different substances (Dussutour and Simpson, 2009; Markin, 1970; Petralia and Vinson, 1978), but no similar mechanism has been yet discovered to explain for differences in thermal traits. In turn, having thermally daring workers might be rewarded with longer foraging times during hotter periods, and larger foraging areas, while the rest of the colony occupies cooler spaces. More thermotolerant species have been found to be more abundant among Mediterranean species (Cerdá et al., 2002). Yet, as a consequence of spending longer times foraging at higher temperatures, the lifespan of average workers might be shorter, compared to workers specialized in bringing water (smaller ants, Ribeiro and Navas, 2008) or defending the colony (the larger ones, Powell and Clark, 2004).

Our results raise methodological concerns on previous values of CTmax, for leaf-cutting ants and potentially other small arthropods. Often, previous studies have warmed ants using a heated ground surface while measuring the temperature right over it, with a probe. This approach generates strong thermal gradients between the ants' body, the heating surface, and the measuring probe. In turn, our system provided homogeneous warming (Figure S5), and that prevented ants from creating a large thermal gradient when raising over their legs. Thus, our results do not support the idea that larger bodies render ants with higher thermal tolerance (Ribeiro et al., 2012), although longer legs might still protect larger ants from heating surfaces (Sommer and Wehner, 2012). Heating ants from below and measuring the temperature at the plate or right over it likely overestimates the CTmax of ants, or other arthropods. Supporting this idea, Ribeiro et al (2012) measured CTmax up to $53^{\circ} \mathrm{C}$, while our maximum CTmax was $48^{\circ} \mathrm{C}$.

While this difference does not invalidate their conclusions, the problematic approach may lead to largely underestimate the true thermal vulnerability of arthropods. When using large global physiological databases, like the GlobTherm (Bennett et al., 2019), such details are difficult to evaluate, as is the case for ant species. For example, Pogonomyrmex desertorum is considered one of the most thermophilic species known $\left(\mathrm{CTmax}=53^{\circ} \mathrm{C}\right)$. In GlobTherm, the data entry is referred to a thesis by A.C. Marsh (1985). However, as others species with CTmax over $50^{\circ} \mathrm{C}$, it was measured in 
such a problematic manner by Whitford and Ettershank (1975). In this way, our results exemplify the critical importance of homogenous warming during the determination of thermal tolerance in arthropods.

We also found that both, relative humidity and hydration level can raise the CTmax of leafcutting ants. Humidity also increased the CTmax of termites (Woon et al., 2018), while hydration has been observed to increase both, the CTmax and VTM of ectothermic vertebrates (e.g. Anderson \& Andrade 2017; Guevara-Molina et al under review, Camacho et al under review). Therefore, hydration may be important for physiological thermal tolerance, across a variety of terrestrial ectotherms.

We know no previous studies that have compared internal and external hydric cues on maximum voluntary temperatures, but leaf-cutting ants seem to react only to internal cues (i.e. hydration level) rather than environmental cues signaling coming hydric stress. These experimental responses add up to previous findings of water stressed ants selecting leaves with higher water content (Bowers and Porter, 1981), and support the idea that behavior will buffer hydric stress in response to the internal hydration state. Future studies should test whether this explanation holds across different organisms, so we can better model their responses to climatic challenges that involving warming and droughts.

Nonetheless, ants adjusted their VTM and CTmax to environmental clues, such like heating rates. The VTM increased with heating rate, in parallel with their CTmax. Yet, total heating time did not, as shown by the lack of effect of the start temperature. Heating time might only become important at sublethal temperatures, and not at the long range studied herein $\left(23^{\circ} \mathrm{C} \sim 30^{\circ} \mathrm{C}\right)$. At temperatures close to the VTM $\left(32^{\circ} \mathrm{C} \sim 33^{\circ} \mathrm{C}\right)$, thermally enhanced processes, like production of free radicals (Luschack, 2011); or dehydration rates (Edney, 1977; Lighton and Bartholomew, 1988), may need time to accumulatively overwhelm homeostatic processes, or for triggering neurological signals of overheating. Adjustment of the VTM to heating rates also happens in at least some species of flies, lizards and amphibians (Terblanche et al. 2007; Camacho et al., 2018; Guevara-Molina et al under review, respectively). To continue understanding integrative responses of organisms to temperature rises, further studies could compare the power of different stressful conditions, such as time at sublethal temperatures, relative humidity, or oxygen availability. Basing these studies on serial on the effects that these factors have on the thermal limits. 
Concluding, we observed how an ectotherm's thermal tolerance responds to environmental and internal cues, in terms of both its behavior (VTM) and physiological limits (CTmax). Leaf-cutting ants became less "heat daring" when dehydrated or if heated more slowly, apparently reacting to an increased risk of overheating, signaled by a lowered CTmax, in both cases. Also, the non-linear

234 effects of their body size on their VTM might have implications for their labor division. Many more 235 studies will be necessary to correctly model how behavioral and physiological thermal tolerance 236 integrates across species, but the urgency to make them is more pressing than ever, given the current

237 climatic trends. With some adjustments, the device we developed should allow estimating the VTM 238 and CTmax for other small ectotherms (e.g. bees, caterpillars, spiders, etc).

\section{List of abbreviations}

BS - Body Size

CTmax - Critical Thermal Maxima

HL - Hydration Level

HR - Heating Rate

ST - Start Temperature

\section{Acknowledgments}

We thank FAPESP and CAPES to finance our study (FAPESP 2018/15664-5). We also thank

247 Prof. Dr. Márcio Reis Custódio and Prof. Dr. Fernando Ribeiro Gomes for letting us conduct our 248 experiments in their laboratory's dependences.

\section{Competing Interest}

The authors declare that the research was conducted in the absence of any commercial or

250 financial relationships that could be construed as a potential competing interest. 


\section{Author Contributions}

252 L., Resources: A. C., A. F. H.; Data curation: C. S. L., A. C.; Data analysis: A. C.; Writing: C. S. L., 253 A. C.; Funding acquisition: C. S. L., A. C., A. F. H.

\section{Funding}

This work was funded by Fundação de Amparo à Pesquisa do Estado de São Paulo (FAPESP grant 2018/15664-5 to C. S. L.). A. C. G. was funded by FAPESP (12/15754-8), CAPES (001) and Marie Curie Grant (897901) during the preparation of this study.

\section{Data availability}

The raw data and supporting figures can be accessed here: 10.6084/m9.figshare.12762038

\section{References}

259 Addo-Bediako, A., Chown, S. L. and Gaston, K. J. (2000). Thermal tolerance, climatic variability 260 and latitude. Proc. Biol. Sci. 267, 739-745. https://doi.org/10.1098/rspb. 2000.1065.

Akaike, H. (1974). A new look at the statistical model identification. IEEE transactions on automatic control. 19(6). 716-723. http://doi.org/10.1109/TAC.1974.1100705.

Anderson, R. C., \& Andrade, D. V. (2017). Trading heat and hops for water: Dehydration effects

264 on locomotor performance, thermal limits, and thermoregulatory behavior of a terrestrial toad.

265 Ecology and evolution. 7(21), 9066-9075. https://doi.org/10.1002/ece3.3219.

266 Angilletta MJ, Wilson RS, Niehaus AC, Sears MW, Navas CA, et al. (2007). Urban Physiology:

267 City Ants Possess High Heat Tolerance. PLoS ONE. 2(2). e258.

268 http://doi.org/10.1371/journal.pone.0000258.

269 Angilletta Jr, M. J., \& Angilletta, M. J. (2009). Thermal adaptation: a theoretical and empirical 270 synthesis. Oxford University Press. 
Michael J. Angilletta, Raymond B. Huey, and Melanie R. Frazier. (2010). Thermodynamic

272 Effects on Organismal Performance: Is Hotter Better? Physiological and Biochemical Zoology. 83, no. 2. 197-206. https://doi.org/10.1086/648567.

Bates, D., Mächler, M., Bolker, B., \& Walker, S. (2014). Fitting linear mixed-effects models using lme4. arXiv preprint arXiv:1406.5823. http://doi.org/10.18637/jss.v067.i01.

Baudier, K. M., Mudd, A. E., Erickson, S. C., \& O'Donnell, S. (2015). Microhabitat and body size effects on heat tolerance: implications for responses to climate change (army ants: Formicidae, Ecitoninae). Journal of Animal Ecology. 84(5). 1322-1330. https://doi.org/10.1111/1365-2656.12388.

Rahbek, C. (2018). GlobTherm, a global database on thermal tolerances for aquatic and terrestrial organisms. Scientific data, 5, 180022. https://doi.org/10.5061/dryad.1cv08.

Bestelmeyer, B. T. (2000). The trade $\square$ off between thermal tolerance and behavioural dominance in a subtropical South American ant community. Journal of Animal Ecology, 69(6), 998-1009. https://doi.org/10.1111/j.1365-2656.2000.00455.x.

Bollazzi, M., \& Roces, F. (2010). Control of nest water losses through building behavior in leafcutting ants (Acromyrmex heyeri). Insectes sociaux, 57(3), 267-273. https://doi.org/10.1007/s00040010-0081-6.

Bowers, M. A., \& Porter, S. D. (1981). Effect of foraging distance on water content of substrates harvested by Atta columbica (Guerin). Ecology, 62(1), 273-275. http://doi.org/10.2307/1936686.

Bilyk, K. T., \& DeVries, A. L. (2011). Heat tolerance and its plasticity in Antarctic

291 fishes. Comparative Biochemistry and Physiology Part A: Molecular \& Integrative Physiology, 158(4), 382-390. https://doi.org/10.1016/j.cbpa.2010.12.010.

Camacho, A., \& Rusch, T. W. (2017). Methods and pitfalls of measuring thermal preference and tolerance in lizards. Journal

of thermal biology, 68, 63-72. 
296 Camacho, A., Rusch, T., Ray, G., Telemeco, R. S., Rodrigues, M. T., \& Angilletta, M. J. (2018).

297 Measuring behavioral thermal tolerance to address hot topics in ecology, evolution, and 298 conservation. Journal of thermal biology, 73, 71-79. https://doi.org/10.1016/j.jtherbio.2018.01.009.

299 Cerdá, X., \& Retana, J. (2000). Alternative strategies by thermophilic ants to cope with extreme

300 heat: individual versus colony level traits. Oikos, 89(1), 155-163. https://doi.org/10.1034/j.1600-

$301 \quad$ 0706.2000.890117.x.

302 Cerdá, X., Retana, J., \& Cros, S. (2002). Critical thermal limits in Mediterranean ant species: 303 trade $\square$ off between mortality risk and foraging performance. Functional Ecology, 12(1), 45-55. 304 https://doi.org/10.1046/j.1365-2435.1998.00160.x.

305 Chown, S. L., Addo-Bediako, A., \& Gaston, K. J. (2002). Physiological variation in insects: large306 scale patterns and their implications. Comparative Biochemistry and Physiology Part B:

307 Biochemistry and Molecular Biology, 131(4), 587-602. $\quad \underline{\text { https://doi.org/10.1016/S1096- }}$ 308 4959(02)00017-9.

309 Chown, S. L., \& Nicolson, S. (2004). Insect physiological ecology: mechanisms and patterns. 310 Oxford University Press.

311 Christian, K. A., \& Morton, S. R. (1992). Extreme thermophilia in a central Australian ant,

312 Melophorus bagoti. Physiological $\quad$ Zoology, $\quad$ 65(5),

313 https://doi.org/10.1086/physzool.65.5.30158548.

314 Cowles, R. B., \& Bogert, C. M. (1944) A preliminary study of the thermal requirements of desert 315 reptiles. Iguana 83: 53.

316 Denlinger, D. L., \& Yocum, G. D. (1998). Physiology of heat sensitivity. In Temperature sensitivity 317 in insects and application in integrated pest management (Vol. 29). Oxford: Westview Press Oxford.

318 Del Toro, I., Ribbons, R. \& Pelini, S. (2012). The little things that run the world revisited: A review 319 of ant-mediated ecosystem services and disservices (Hymenoptera: Formicidae). Myrmecological 320 News. 17. 133-146.

321 Dussutour, A., \& Simpson, S. J. (2009). Communal nutrition in ants. Current Biology, 19(9), 740322 744. https://doi.org/10.1016/j.cub.2009.03.015. 
323 Edney, E. B. (2012). Water balance in land arthropods (Vol. 9). Springer Science \& Business 324 Media.

325 Feener Jr, D. H., \& Lighton, J. R. (1991). Is foraging in the desert ant, Messor pergandei

326 (Hymenoptera: Formiceidae), limited by water? Ecological entomology, 16(2), 183-191.

327 https://doi.org/10.1111/j.1365-2311.1991.tb00208.x.

328 Galbreath, P. F., Adams, N. D., \& Martin, T. H. (2004). Influence of heating rate on measurement 329 of time to thermal maximum in trout. Aquaculture, 241(1-4), 587-599.

330 https://doi.org/10.1016/j.aquaculture.2004.08.004.

331 Gamboa, G. J. (1976). Effects of temperature on the surface activity of the desert leaf-cutter ant, 332 Acromyrmex versicolor versicolor (Pergande) (Hymenoptera: Formicidae). American Midland 333 Naturalist, 485-491. http://doi.org/10.2307/2424417.

334 Hölldobler, B., \& Wilson, E. O. (1990). The ants. Harvard University Press.

335 Huey, R. B., Bennett, A. F., John-Alder, H., \& Nagy, K. A. (1984). Locomotor capacity and 336 foraging behaviour of Kalahari lacertid lizards. Animal Behaviour, 32(1), 41-50. 337 https://doi.org/10.1016/S0003-3472(84)80322-X.

338 Huey, R. B., \& Stevenson, R. D. (1979). Integrating thermal physiology and ecology of ectotherms: 339 a discussion of approaches. American Zoologist, 19(1), 357-366.

340 https://doi.org/10.1093/icb/19.1.357.

341 Hurlbert, A. H., Ballantyne IV, F. O. R. D., \& Powell, S. (2008). Shaking a leg and hot to trot: the 342 effects of body size and temperature on running speed in ants. Ecological Entomology, 33(1), 144343 154. https://doi.org/10.1111/j.1365-2311.2007.00962.x.

344 Jensen, T.F. \& Nielsen, M. (1975). The influence of body size and temperature on worker ant 345 respiration. Natura Jutlandica. 18. 21-25.

346 Johnson, R. A. (2000). Habitat segregation based on soil texture and body size in the seed $\square$ harvester 347 ants Pogonomyrmex rugosus and P. barbatus. Ecological Entomology, 25(4), 403-412. 348 https://doi.org/10.1046/j.1365-2311.2000.00286.x. 
Jørgensen, L. B. , Robertson, R. M. and Overgaard, J. (2020) Neural dysfunction correlates with heat coma and CTmax in Drosophila but does not set the boundaries for heat stress survival. Journal of Experimental Biology 223: jeb218750. https://doi.org/10.1242/jeb.218750.

352 Kaspari, M. (1993). Body size and microclimate use in Neotropical granivorous ants. Oecologia, 96(4), 500-507. https://doi.org/10.1007/BF00320507.

354 Kaspari, M., \& Weiser, M. D. (1999). The size-grain hypothesis and interspecific scaling in ants. Functional ecology, 13(4), 530-538. https://doi.org/10.1046/j.1365-2435.1999.00343.x.

Lighton, J. R. B., \& Bartholomew, G. A. (1988). Standard energy metabolism of a desert harvester ant, Pogonomyrmex rugosus: effects of temperature, body mass, group size, and humidity. Proceedings of the National Academy of Sciences,85(13), 4765-4769. https://doi.org/10.1073/pnas.85.13.4765.

Lighton, J. R., \& Quinlan, M. C. (1994). Is bigger better? Water balance in the polymorphic desert harvester ant Messor https://doi.org/10.1111/j.1365-3032.1994.tb01059.x.

363 Lushchak, V. I. (2011). Environmentally induced oxidative stress in aquatic animals. Aquatic toxicology, 101(1), 13-30. https://doi.org/10.1016/j.aquatox.2010.10.006.

365 Markin, G.P. (1970). Food distribution within laboratory colonies of the argentine ant, Tridomyrmex humilis (Mayr). Ins. Soc 17, 127-157. https://doi.org/10.1007/BF02223074.

367 Marsh, A. C. (1985). Aspects of the ecology of Namib Desert ants. Thesis., University of Cape 368 Town, Faculty of Science, Department of Biological Sciences.

369 Mora, C., \& Maya, M. F. (2006). Effect of the rate of temperature increase of the dynamic method 370 on the heat tolerance of fishes. Journal of Thermal Biology,31(4), 337-341. 371 https://doi.org/10.1016/j.jtherbio.2006.01.005.

372 O'Neill, K. M., \& Kemp, W. P. (1990). Worker response to thermal constraints in the ant Formica 373 obscuripes (Hymenoptera: Formicidae). Journal of thermal biology, 15(2), 133-140. 374 https://doi.org/10.1016/0306-4565(90)90030-L. 

N. K. (2014). Climate change 2014: synthesis report. Contribution of Working Groups I, II and III to the fifth assessment report of the Intergovernmental Panel on Climate Change (p. 151). Ipcc.

Petralia, R. S. \& Vinson., S. B. (1978). Feeding in the Larvae of the Imported Fire Ant, Solenopsis invicta: Behavior and Morphological Adaptations, Annals of the Entomological Society of America, 71 - 4, 643-648. https://doi.org/10.1093/aesa/71.4.643.

381 Pinheiro J, Bates D, DebRoy S, Sarkar D and R Core Team (2017). nlme: Linear and Nonlinear Mixed Effects Models. $\mathrm{R}$ package version 3.1-131, <URL: https://CRAN.R383 project.org/package=nlme> .

384 Powell, S., \& Clark, E. (2004). Combat between large derived societies: a subterranean army ant established as a predator of mature leaf-cutting ant colonies. Insectes Sociaux, 51(4), 342-351.

R Core Team (2018). R: A language and environment for statistical computing. R Foundation for Statistical Computing, Vienna, Austria. URL: http://www.R-project.org/.

Rezende, E. L., Tejedo, M., \& Santos, M. (2011). Estimating the adaptive potential of critical thermal limits: methodological problems and evolutionary implications. Functional Ecology, 25(1), 111-121. https://doi.org/10.1111/j.1365-2435.2010.01778.x.

391 Ribeiro, P. L., Camacho, A., \& Navas, C. A. (2012). Considerations for assessing maximum critical temperatures in small ectothermic animals: insights from leaf-cutting ants. PLoS One, 7(2). http://doi.org/10.1371/journal.pone.0032083.

Ribeiro, P. L., \& Navas, C. A. (2008). Colony dehydration and water collection by specialized caste in the leaf-cutting ant Atta sexdens rubropilosa. Journal of insect behavior, 21(6), 549-558. https://doi.org/10.1007/s10905-008-9150-3. implications of thermo $\square$ hydroregulation in terrestrial ectotherms. Ecology and evolution, 9(17), 10029-10043. https://doi.org/10.1002/ece3.5440.

Sommer, S., \& Wehner, R. (2012). Leg allometry in ants: extreme long-leggedness in thermophilic 
Terblanche, J. S., Deere, J. A., Clusella-Trullas, S., Janion, C., \& Chown, S. L. (2007). Critical thermal limits depend on methodological context. Proceedings of the Royal Society B: Biological Sciences, 274(1628), 2935-2943. https://doi.org/10.1098/rspb.2007.0985.

406

Tizón, R., Wulff, J. P., \& Peláez, D. V. (2014). The effect of increase in the temperature on the 407 foraging of Acromyrmex lobicornis (Hymenoptera: Formicidae). Zoological Studies, 53(1), 40. 408 https://doi.org/10.1186/s40555-014-0040-4.

409 Vinagre, C., Leal, I., Mendonça, V., \& Flores, A. A. (2015). Effect of warming rate on the critical 410 thermal maxima of crabs, shrimp and fish. Journal of thermal biology, 47, 19-25. 411 https://doi.org/10.1016/j.jtherbio.2014.10.012.

412 Verble-Pearson, R. M., Gifford, M. E., \& Yanoviak, S. P. (2015). Variation in thermal tolerance 413 of North American ants. Journal of thermal biology, 48, 65-68. 414 https://doi.org/10.1016/j.jtherbio.2014.12.006.

415 Walthers, G. R., Post, E., Convey, P., Menzel, A., Parmesan, C., Beebee, T. J., ... \& Bairlein, F. 416 (2002). Ecological responses to recent climate change. Nature, 416, 389-395. 417 http://doi.org/10.1038/416389a.

418 Wehner, R. (1983). Taxonomie, Funktionsmorphologie und Zoogeographie der saharischen 419 Wüstenameise Cataglyphis fortis (Forel 1902) stat. nov. Senckenbergiana biol, 64, 89-132.

420 Wehner, R., Marsh, A. C., \& Wehner, S. (1992). Desert ants on a thermal 421 tightrope. Nature, 357(6379), 586-587. https://doi.org/10.1038/357586a0.

422 Wiens, J. J., Camacho, A., Goldberg, A., Jezkova, T., Kaplan, M. E., Lambert, S. M., ... \& 423 Walls, R. L. (2019). Climate change, extinction, and Sky Island biogeography in a montane lizard. 424 Molecular ecology, 28(10), 2610-2624. https://doi.org/10.1111/mec.15073.

425 Williams, S. E., Shoo, L. P., Isaac, J. L., Hoffmann, A. A., \& Langham, G. (2008). Towards an 426 integrated framework for assessing the vulnerability of species to climate change. PLoS 427 biology, 6(12). https://doi.org/10.1371/journal.pbio.0060325.

428 Wilson, E. O. (1980). Caste and division of labor in leaf-cutter ants (Hymenoptera: Formicidae: 429 Atta). Behavioral ecology and sociobiology, 7(2), 157-165. https://doi.org/10.1007/BF00299521. 
430 Woon, J. \& Boyle, Michael \& Ewers, R. \& Chung, Arthur \& Eggleton, Paul. (2018). Termite 431 environmental tolerances are more linked to desiccation than temperature in modified tropical forests.

432 Insectes Sociaux. https://10.1007/s00040-018-0664-1.v.

\section{Figures}

\section{The Thermal Tolerance Meter}
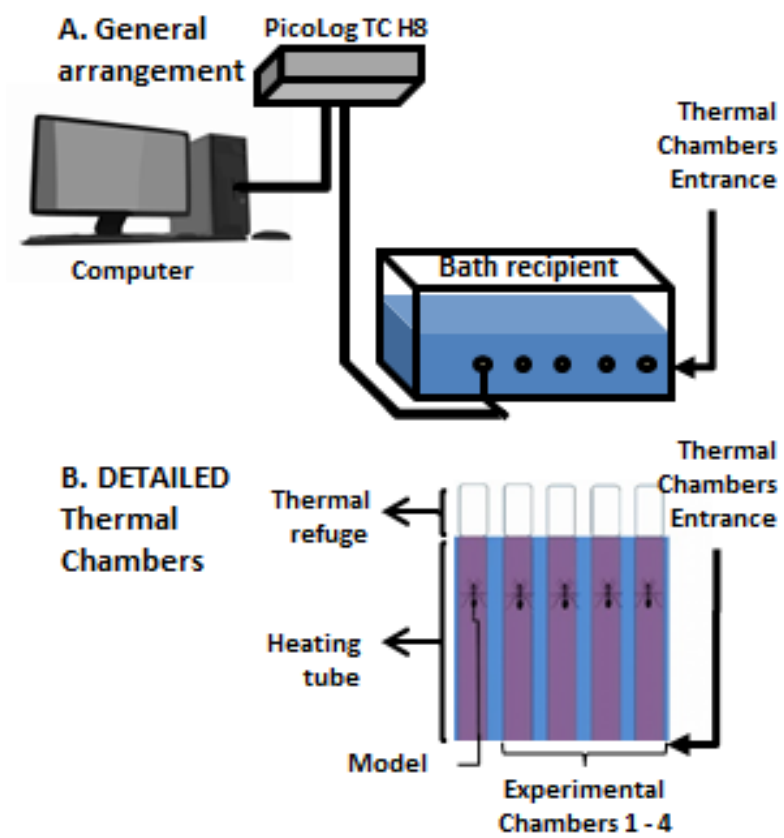

434 Figure 1 | The Thermal Tolerance Meter. A) General view of all experimental arrangement B) In a 435 detailed view is possible to see 5 chambers, 1 for the model and 4 experimental. 

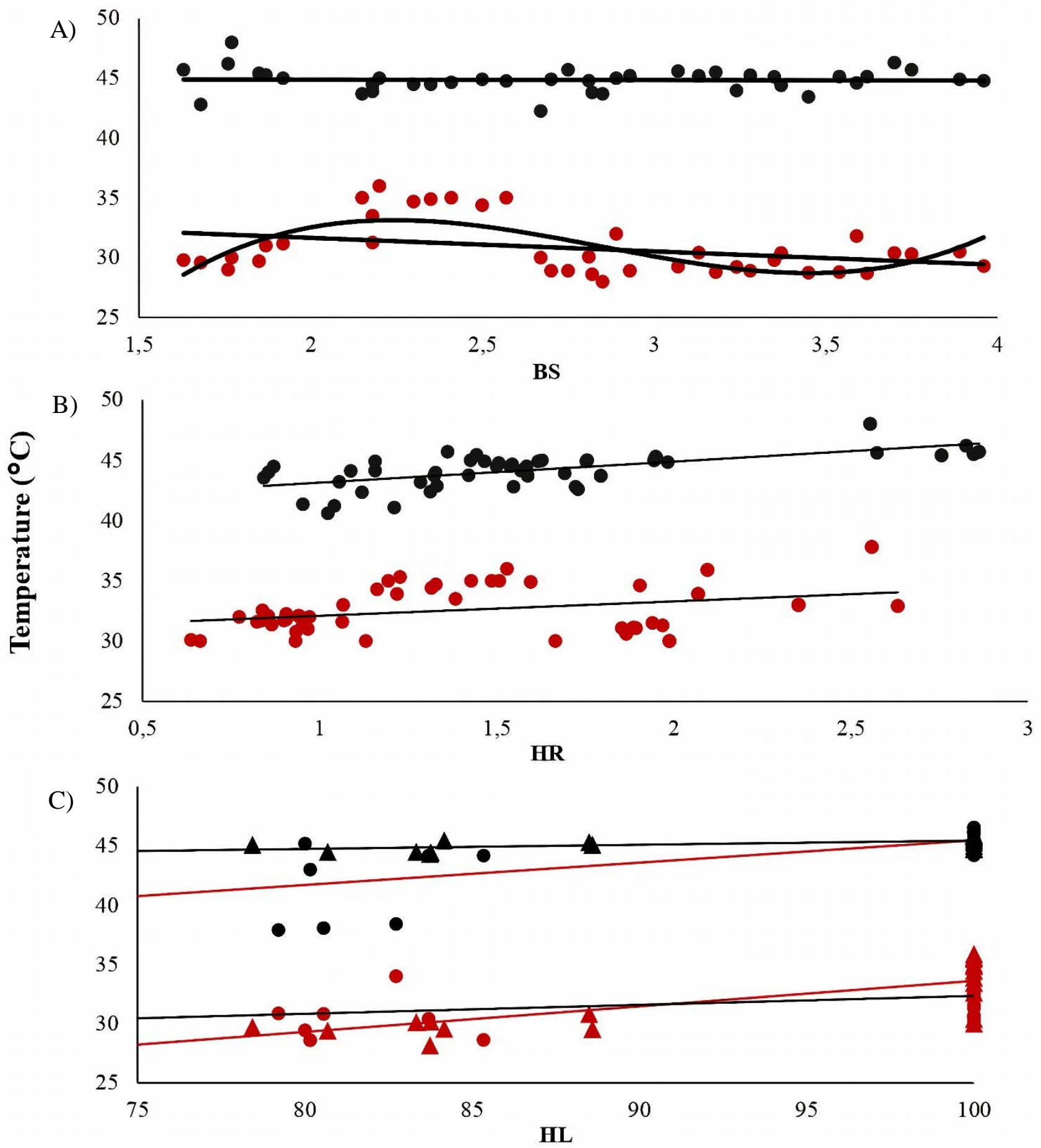

HL

437 Figure 2 | Relationships of ants' VTM (in red) and CTmax (in black) with several factors. (A)

438 While CTmax remained unaltered by body size (in $\mathrm{mm}$ of head width), the VTM of average-sized

439 workers is higher than of their sisters; (B) Heating rates (in ${ }^{\circ} \mathrm{C} /$ minute) also increase both, the VTM

440 and the CTmax linearly. Finally, (C) while body hydration level (in \%) was important to increase

441 both, the VTM and the CTmax, only the latter was altered by the relative humidity of the tubes. 
bioRxiv preprint doi: https://doi.org/10.1101/2020.08.04.236844; this version posted August 4, 2020. The copyright holder for this preprint (which was not certified by peer review) is the author/funder. All rights reserved. No reuse allowed without permission.

Ants' responses to temperature rises

442 Black tendency lines and $\bullet$ represent the treatment at 50\% relative humidity. Red tendency lines and

$443 \Delta$ represent the treatment at $85 \%$ relative humidity. 